\title{
Interface Behavior of Copper and Steel by Plasma-MIG Hybrid Arc Welding
}

\author{
Tao YANG, Hongming GAO ${ }^{\dagger}$, Shenghu ZHANG and Lin WU \\ State Key Laboratory of Advanced Welding and Joining, Harbin Institute of Technology, Harbin 150001, China \\ [Manuscript received 14 September 2012, in revised 10 January 2013] \\ (c) The Chinese Society for Metals and Springer-Verlag Berlin Heidelberg
}

\begin{abstract}
Plasma-MIG hybrid arc welding is a hybrid heating source welding method which is composed of plasma arc and MIG arc. During Plasma-MIG hybrid arc welding process, the interface behavior of copper and steel dissimilar alloy is investigated. The results show that electromagnetic stirring effect decreases and the heat input increases with the increase of outer plasma current in the hybrid arc welding process. The interface diffusion and interface thickness is controlled by the tradeoff of electromagnetic stirring effect degradation and heat input increase. The interface diffusion and interface thickness are controlled by decreasing the electromagnetic stirring force and increasing the heat input with the increase of plasma current in $\mathrm{Cu} / \mathrm{Fe}$ plasma-MIG hybrid arc welding process.
\end{abstract}

KEY WORDS: Plasma-MIG hybrid arc; Copper-steel dissimilar alloy; Interface behavior

\section{Introduction}

For $\mathrm{Cu}$ /steel dissimilar metals welding, the atom diffusion of the filler metal and weld/substrate interface thickness should be restricted to a low level in order to obtain a microstructure of the weld similar to the filler metal. In gas metal arc welding (GMAW) process, with the increase of the welding current, consequently the heat input and electromagnetic stirring effect on the base metal increase. By increasing the heat input, interface diffusion rate and substrate melting rate increase, and therefore the interface diffusion capability was enhanced. The interface diffusion capability increases for a high convection of the substrates by increasing the electromagnetic stirring effect, so the mechanical properties of the weld decline ${ }^{[1,2]}$. Therefore, the interface diffusion control is a key point in $\mathrm{Cu}$ /steel dissimilar metals welding process with high heat input.

Plasma-MIG hybrid arc welding is a promising hybrid heating source welding method with the highlight of the coupling of plasma arc and MIG arc.

† Corresponding author. Prof.; Tel: +86 45186415537 ;

E-mail address: yt19821105@163.com (Hongming GAO)

DOI: $10.1007 / \mathrm{s} 40195-012-0159-4$
The dry extension of the electrode is long due to the unique welding torch structure, and the central temperature is high as a result of the compression effect during welding, leading to high melting rate of wire. And also, the interaction between the inner MIG arc and the outer plasma arc due to the coupling effect makes the welding characteristics of plasma-MIG hybrid welding versatile. During welding, the MIG arc, droplet and tip of the wire are all surrounded by plasma arc which not only plays the role of heating wire, but also changes load case of droplet and path of current ${ }^{[3]}$. Therefore, many characteristics of this method is displayed ${ }^{[4-6]}$, such as high melting rate, stable $^{[7]}$ and spatter free welding process ${ }^{[8-11]}$. In this paper, the joining $\mathrm{Cu}$ /steel dissimilar metals is conducted by plasma-MIG hybrid welding method, and the effects of the hybrid arc on electromagnetic stirring of the weld pool and the interface diffusion are investigated. Interface diffusion for $\mathrm{Cu} /$ steel dissimilar metals joining is well controlled in plasma-MIG hybrid arc welding process with high heat input.

\section{Experimental}

Table 1 shows the compositions of filler metal and base metal in detail. Low-carbon steel is used as base 
metal for surface welding experiment, and filler metal HS201 with the diameter of $1.2 \mathrm{~mm}$ are adopted as MIG electrodes for inner MIG arc.

Table 1 Compositions (wt\%) of base metal and filler metal

\begin{tabular}{ccccccccc} 
and filler metal & & & & & \\
\hline Material & $\mathrm{C}$ & $\mathrm{Mn}$ & $\mathrm{Si}$ & $\mathrm{Cu}$ & $\mathrm{Fe}$ & $\mathrm{Sn}$ & $\mathrm{P}$ \\
\hline Base metal & 5.5 & 4.2 & $\leq$ & 0.3 & 0 & 90.9 & 0 & 0.12 \\
Filler metal (HS201) & 0 & 0.4 & 0.4 & 98.9 & 0 & 1.1 & 0
\end{tabular}

Plasma-MIG hybrid arc welding system used in this paper is self-developed as shown in Fig. 1. Two power source are used $\mathrm{C}$ one with a horizontal current characteristic of the plasma arc and the other with a horizontal voltage for the MIG arc ${ }^{[12]}$. Sixth-freedom robot and in-house developed control system are used for the coupling arcs and welding process control. The coaxial nozzle with water cooling is used in PlasmaMIG welding torch. Welding sequence control and collection of electrical parameters are realized by embedded industrial computer.

\section{Results and Discussion}

\subsection{Coupling relation of plasma-MIG hybrid arc}

Fig. 2 shows the sketch map of the plasma-MIG hybrid arc, and the outer layer of the hybrid arc is highly compressed plasma arc with high temperature.

Plasma arc and MIG arc do not function independently, and they establish close coupling relation with each other by sharing wire, electromagnetic space and conducting atmosphere. In the welding process, the outer plasma arc which is compressed by nozzle makes the plasma-MIG hybrid arc current density enhance. Therefore, the outer plasma arc has great compression effect on the inner MIG arc ${ }^{[13,14]}$. For the existence of the conductive atmosphere in the plasma arc, the hybrid arc characteristics changes, and the interaction between the plasma arc and MIG arc is attributed to the electromagnetic compression effect. Fig. 3 shows the voltage and current waveforms of the MIG arc with various plasma current in hybrid arc welding. as shown in Fig. 3(a)). With the in-

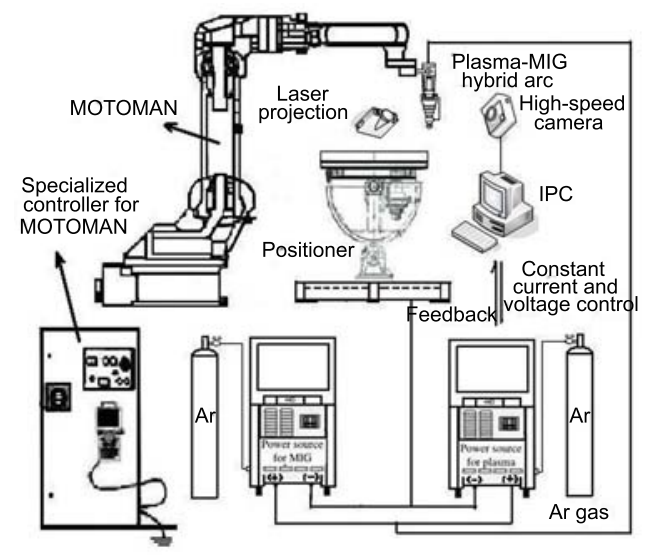

Fig. 1 Schematic illustration of Plasma-MIG hybrid arc welding system

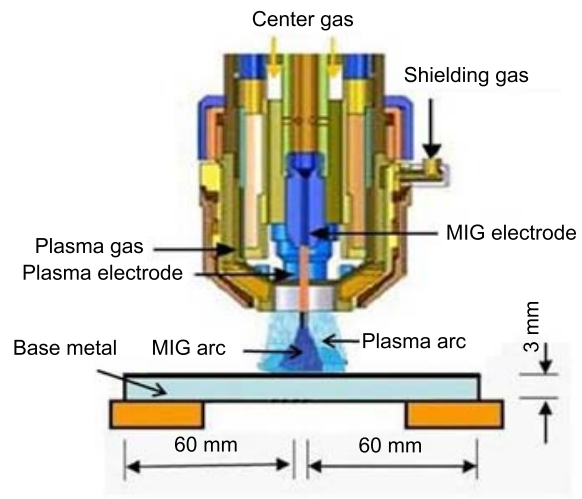

Fig. 2 Modeling of Plasma-MIG hybrid arc

crease of the outer plasma current, the electromagnetic compression force on the MIG arc is enhanced, and therefore the inner MIG arc fluctuates with the change of the compression effect. In Fig. 3(d)), due to the increase of electromagnetic force with the use of an high plasma current, MIG current fluctuates much heavier than with an low plasma current, and the interaction between the plasma arc and MIG arc is also stronger. With the same wire feeding speed, the MIG current declines by increasing the plasma current in hybrid arc welding process.

The electromagnetic stirring effect on the weld pool is mainly attributed to the MIG arc in plasmaMIG hybrid arc welding process, and the pressure $(P)$ on any point of the weld pool is illustrated by the following formula ${ }^{[15]}$

$$
P=\frac{2 I^{2}}{\pi l^{2}(1-\cos \theta)^{2}} \ln \frac{\cos \frac{\varphi}{2}}{B}
$$

where $I$ is current of MIG arc, $L$ is arc length, $\varphi$ is cone angle of data points to vertex, $\theta$ is cone angle of hybrid arc.

By integrating the formula above, the force $F_{\text {a per- }}$ pendicular to the weld pool by the hybrid arc is given by

$$
F_{\mathrm{a}}=\frac{4 I^{2}}{(1-\cos \theta)^{2}} \int_{0}^{\theta} \sin ^{2} \varphi \ln \frac{\cos \frac{\varphi}{2}}{B} \mathrm{~d} \varphi
$$

The force $F_{\mathrm{a}}$ is proportional to $\left(I_{1}+I_{2}\right) \times \Delta I$, where $I_{1}+I_{2}$ represents the effect of MIG current on the electromagnetic stirring force, and $\Delta I$ represents the effect of MIG current fluctuation extent on the electromagnetic stirring force. The electromagnetic stirring force decreases with the increase of the plasma current, and the MIG current fluctuation extent increases with the increase of the plasma current, and therefore $\Delta I$ increases. So the electromagnetic stirring effect by the hybrid arc on the weld pool descends more and more apparent with the increase of plasma current.

\subsection{Effects of hybrid arc on Interface diffusion behav- ior}

In hybrid arc welding process, plasma arc current is related to the arc length, so the heat input $Q$ to the 

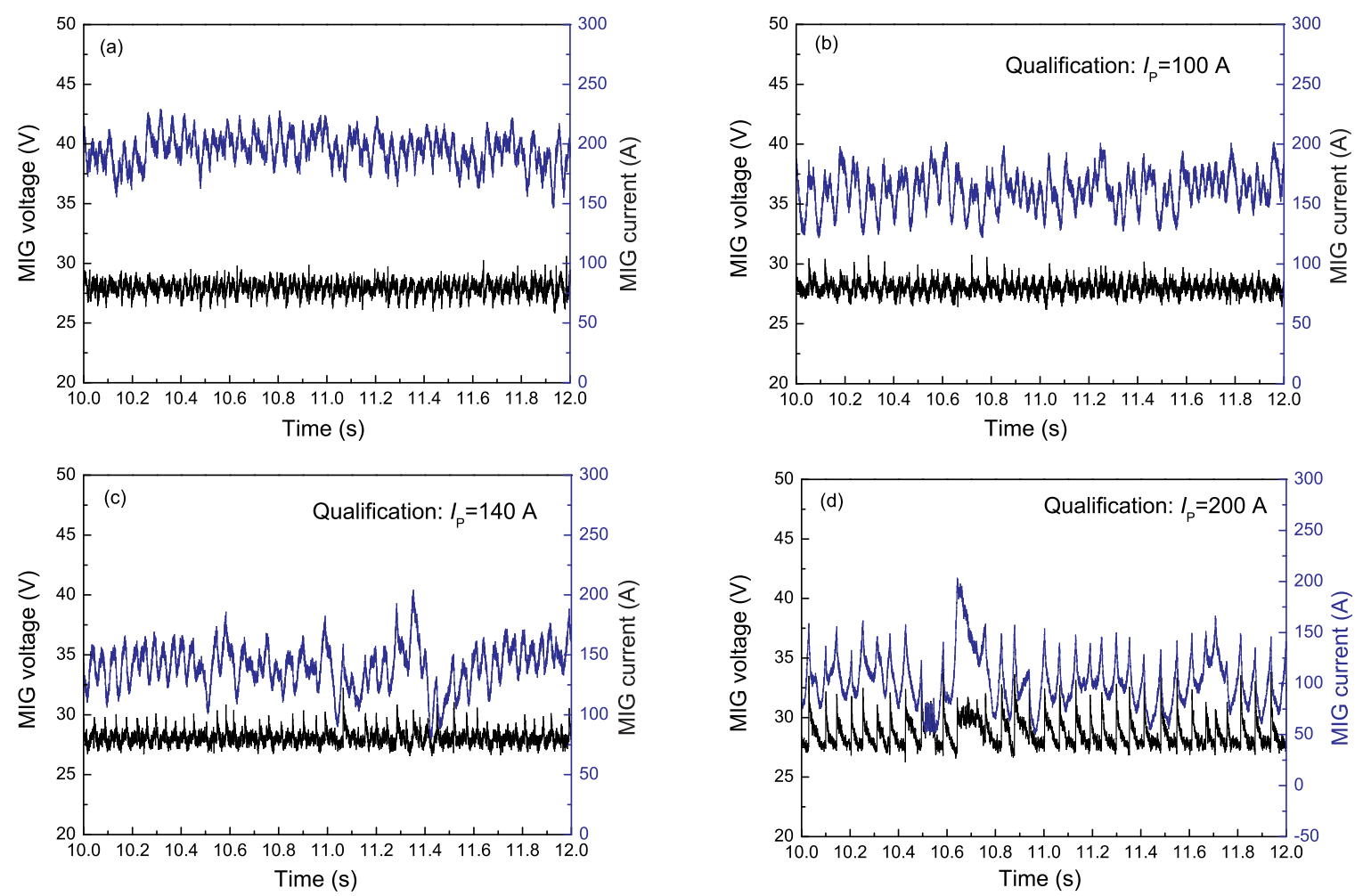

Fig. 3 Voltage and current waveform of inner MIG arc with different outer plasma currents: (a) MIG; (b) $I_{\mathrm{P}}=100 \mathrm{~A} ;\left(\right.$ c) $I_{\mathrm{P}}=140 \mathrm{~A} ;$ (d) $I_{\mathrm{P}}=200 \mathrm{~A}$

weld pool by the hybrid arc is given by

$$
Q=\frac{\varphi\left(U_{\mathrm{M}} \times I_{\mathrm{M}}+U_{\mathrm{P}} \times I_{\mathrm{P}}\right)}{V}
$$

where $\varphi$ is the heat efficiency, $V$ is welding speed, $U_{\mathrm{M}}$ is MIG voltage, $I_{\mathrm{M}}$ is MIG current, $U_{\mathrm{P}}$ is plasma voltage, $I_{\mathrm{P}}$ is plasma current.

Hybrid arc welding transfers to MIG arc welding when plasma current $I_{\mathrm{P}}$ equals to zero. Heat input increases by increasing the plasma current while MIG voltage and plasma voltage are $28 \mathrm{~V}$ and $38 \mathrm{~V}$, respectively.

Fig. 4 shows the SEM images of the weld interface with the use of different plasma current values in hybrid arc welding, with the MIG current of $28 \mathrm{~V}$ and plasma current of $38 \mathrm{~V}$. The atom radius, lattice pattern and crystal constant for $\mathrm{Fe}$ and $\mathrm{Cu}$ are similar to each other, so the two metals can totally dissolve each other in liquid state and limited dissolve each other in solid state. In MIG welding process, the high electromagnetic stirring effect can promote the diffusion of $\mathrm{Fe}$ into $\mathrm{Cu}$ metal, and a large quantity of $\alpha(\mathrm{Fe})+\varepsilon(\mathrm{Cu})$ solid solution is obtained, as is shown in Fig. 4(a)). The heat input increases with the increase of the plasma current. The concentration of $\alpha(\mathrm{Fe})+\varepsilon(\mathrm{Cu})$ solid solution in the $\mathrm{Cu}$ weld declines apparently when the plasma current is $60 \mathrm{~A}$, as is shown in Fig. 4(b)). on the contrary, the concentration of $\alpha(\mathrm{Fe})+\varepsilon(\mathrm{Cu})$ solid solution in the $\mathrm{Cu}$ weld increases by further increasing the heat input, as is shown in Fig. 4(c)) and Fig. 4(d)). As the plasma current is $200 \mathrm{~A}$, a high amount of base metals are melted, and the liquid $\mathrm{Fe}$ accumulates in the $\mathrm{Cu}$ weld zone. It can be concluded that plasma current can reduce the electromagnetic stirring effect of the hybrid arc on the weld pool to resist the diffusion of $\mathrm{Cu}$ and Fe into each other, but the increase of the heat input due to the introduce of plasma current promotes the diffusion phenomenon. In hybrid arc welding, the diffusion of $\mathrm{Fe}$ into $\mathrm{Cu}$ weld is controlled by increasing plasma current to reduce the electromagnetic stirring effect and restricting the heat input.

\subsection{Effects of hybrid arc on Interface width}

In surface overlaying of $\mathrm{Cu}$ on $\mathrm{Fe}$, the surface layer is mainly liquid $\mathrm{Cu}$ metal with low electromagnetic stirring effects and heat input. The diffusion of $\mathrm{Fe}$ into $\mathrm{Cu}$ liquid surface layer is conducted in the manner of solid/liquid diffusion to form the interface, and the interface thickness is quite small due to high diffusion activation energy of $\mathrm{Fe}$ into $\mathrm{Cu}$. With the increase of the electromagnetic stirring effect and heat input, the Fe base metal melts, and the surface layer is composed of liquid $\mathrm{Fe}$ and $\mathrm{Cu}$. Liquid $\mathrm{Fe}$ is mixed with liquid $\mathrm{Cu}$ by the electromagnetic stirring effect, so Fe solid solution is formed in the weld to form the interface with a big thickness. Therefore, the effect of electromagnetic stirring on the weld pool and the effect of heat input on the interface diffusion can be 


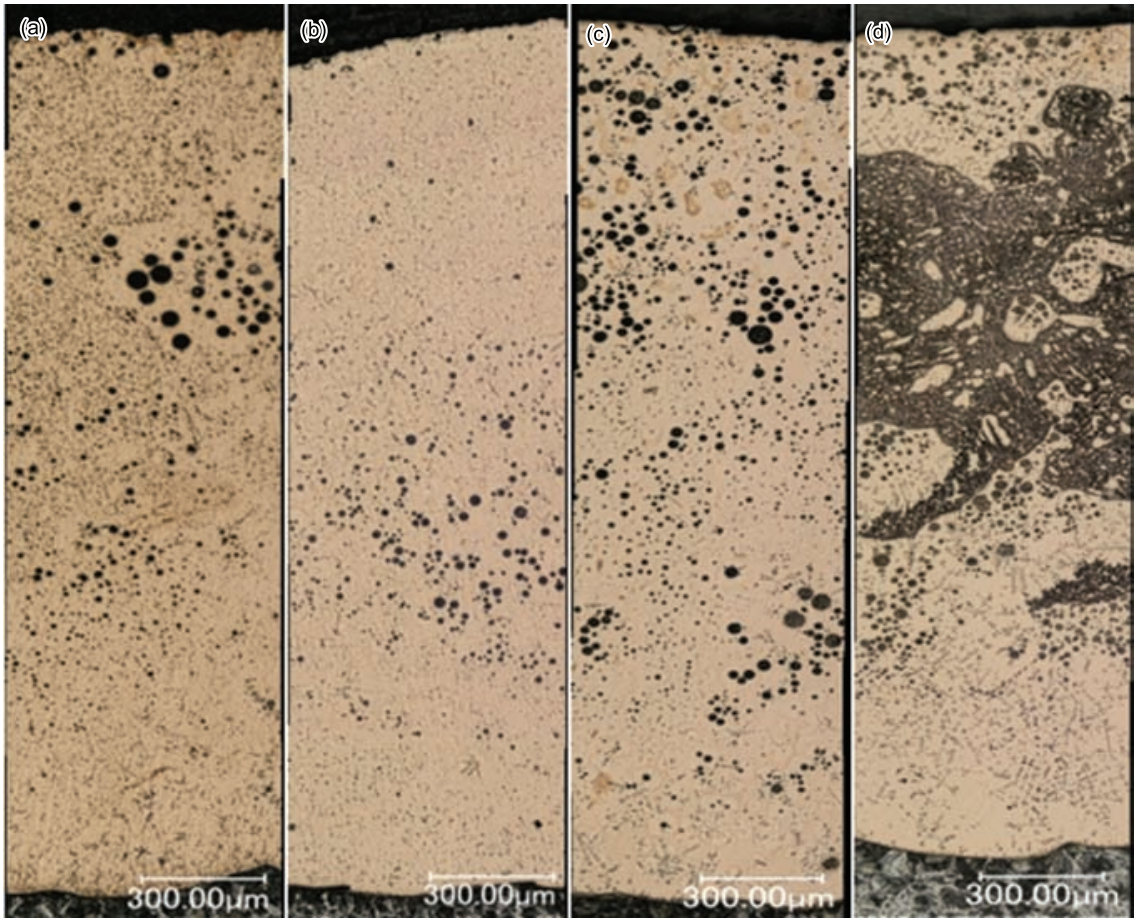

Fig. 4 Effects of hybrid arc on interface diffusion behavior: (a) MIG; (b) $I_{\mathrm{P}}=60 \mathrm{~A}$; (c) $I_{\mathrm{P}}=120 \mathrm{~A}$; (d) $I_{\mathrm{P}}=200 \mathrm{~A}$ (MIG voltage is $28 \mathrm{~V}$; Plasma voltage is $38 \mathrm{~V}$ )

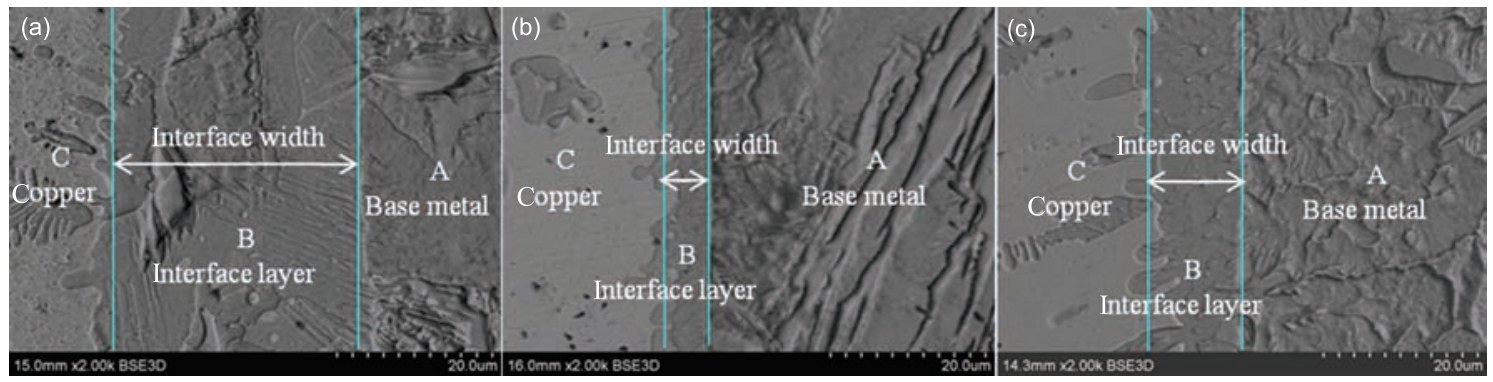

Fig. 5 Interface width with different plasma currents: (a) MIG; (b) $I_{\mathrm{P}}=60 \mathrm{~A}$; (c) $I_{\mathrm{P}}=120 \mathrm{~A}$

characterized by the change of the interface thickness.

The interface thickness firstly decrease, and then increase with the increase of the plasma current, as is shown in Fig. 5. In the hybrid arc welding process, the electromagnetic stirring force decreases to resist interface diffusion, and the heat input increases to promote interface diffusion with the increase of the plasma current, so the interface thickness is a tradeoff between the electromagnetic stirring force and heat input.

Fig. 6 shows the variations of the interface thickness with the plasma current and heat input, and it can be seen that a minimum interface thickness is available with the heat input of about $5 \times 10^{5} \mathrm{~J} / \mathrm{m}$. so the interface thickness has a minimum value with the increase of the plasma current in the hybrid arc welding process. The critical value of the heat input for the minimum interface layer depth can be obtained by analyzing the relationship between the heat input and interface layer depth. From Eq. (3) which describes the relationship between the heat input and the plasma current, the critical current for the minimum interface layer depth can be derived. The results

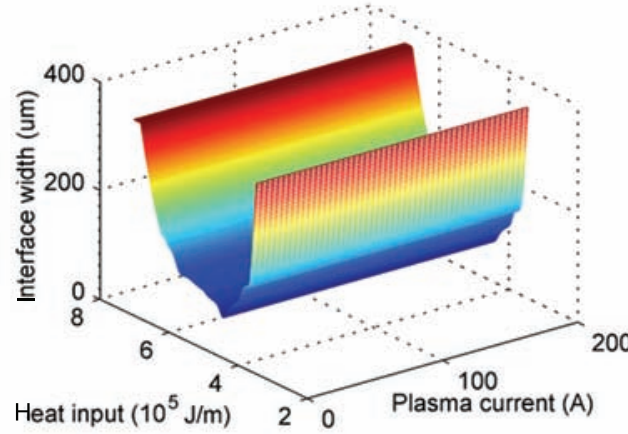

Fig. 6 Effects of plasma current and the heat input on interface width

show that in $\mathrm{Cu} / \mathrm{Fe}$ hybrid arc welding process, there exists a threshold value for the outer plasma current to get a minimum interface thickness with a high heat input value.

\section{Conclusions}

(1) The electromagnetic stirring effect on the weld 
pool decrease with the increase of the plasma current.

(2) In hybrid arc welding, the electromagnetic stirring effect of the hybrid arc on the weld pool to resist the diffusion of $\mathrm{Cu}$ and Fe into each other can be reduced by plasma current, but the increase of the heat input due to the introduce of plasma current promotes the diffusion phenomenon.

(3) In $\mathrm{Cu} / \mathrm{Fe}$ hybrid arc welding process, the electromagnetic stirring force decreases to resist interface diffusion, and the heat input increases to promote interface diffusion with the increase of the plasma current. There exists a threshold value for the outer plasma current to get a minimum interface thickness with a high heat input value.

\section{Acknowledgements}

This work was financially supported by the National Natural Science Foundation of China (Nos. 50974046 and 50904020), and the Twelfth Five-year Aerospace Project of China.

\section{REFERENCES}

[1] S.X. Lu, S.Q. Yang and T. Yang, Trans. China Weld. Inst. 28(12) (2007) 101.
[2] Z.S. Yu and Y. Qian, Mater. Sci. Technol. 9 (2002) 1045.

[3] H. Terasaki and S.W. Simpson, Sci. Technol. Weld. Join. 10 (2005) 120.

[4] G. Jelmorini, G.W. Ticheelaar and W.G. Essers, Met. Constr. 7(11) (1975) 568.

[5] Anon. Welding and Metal Fabrication 49(8) (1981) 465.

[6] W.G. Essers and A.C. Liefkens, Mach. Prod. Eng. 12 (1972) 632.

[7] E. Baune, C. Bonnet and S. Liu, Sci. Technol. Weld. Join. 6(3) (2001) 139.

[8] André Alves de Resende, Valtair Antonio Ferraresi, Américo Scotti and Jair Carlos Dutra, Sold gem Insp. São Paulo 12(2) (2007) 89.

[9] H.C. de Miranda, A. Scotti and V.A. Ferraresi, Sci. Technol. Weld. Join. 12(3) (2007) 249.

[10] V.P. Fed'ko and A.S. Chipalyuk, Weld. Int. 17 (2003) 550.

[11] P. Zhu, M. Rados and S.W. Simpson, Plasma Sources: Sci. Technol. 4 (1995) 495.

[12] K. Ono, Z.J. Liu, T. Era, T. Uezono, T. Ueyama, M. Tanaka and K. Nakata, Weld. Int. 23 (2008) 805.

[13] Mosie Alves de Oliveira, Jair Carlos Dutra, Weld. Cut. 6 (2005) 324.

[14] J.H. Waszink and M.J. Piena, Weld. J. 62(4) (1983) 108.

[15] J.C. Amson, Brit. Weld. J. 62(4) (1983) 108. 